\title{
Predictors of mortality in COVID-19 patients at Kinshasa Medical Center and a survival analysis: a retrospective cohort study
}

Yannick Nlandu ${ }^{1,2^{*}}$ D , Danny Mafuta ${ }^{1}$, Junior Sakaji ${ }^{1}$, Melinda Brecknell ${ }^{1}$, Yannick Engole ${ }^{1,2}$, Jessy Abatha ${ }^{1}$, Jean-Robert Nkumu', Aliocha Nkodila ${ }^{3}$, Marie-France Mboliassa ${ }^{1,2}$, Olivier Tuyinama', Dauphin Bena', Yves Mboloko', Patrick Kobo', Patrick Boloko', Joseph Tshangu', Philippe Azika', Jean-Pierre Kanku', Pally Mafuta', Magloire Atantama', Jean-Michel Mavungu' ${ }^{1}$, Rosita Kitenge ${ }^{1}$, Asma Sehli ${ }^{1}$, Karel Van Eckout ${ }^{1}$, Cathy Mukuku', Léo Bergeret ${ }^{1}$, David Benchetritt ${ }^{1}$, Golan Kalifa ${ }^{1}$, Ahmed Rodolphe ${ }^{1}$ and Justine Bukabau ${ }^{1,2}$

\begin{abstract}
Background: Despite it being a global pandemic, there is little research examining the clinical features of severe COVID-19 in sub-Saharan Africa. This study aims to identify predictors of mortality in COVID-19 patients at Kinshasa Medical Center (KMC).

Methods: In this retrospective, observational, cohort study carried out at the Kinshasa Medical Center (KMC) between March 10, 2020 and July 10, 2020, we included all adult inpatients ( $\geq 18$ years old) with a positive COVID-19 PCR result. The end point of the study was survival. The study population was dichotomized into survivors and nonsurvivors group. Kaplan-Meier plot was used for survival analyses. The Log-Rank test was employed to compare the survival curves. Predictors of mortality were identified by Cox regression models. The significance level of $p$ value was set at 0.05 .
\end{abstract}

Results: 432 patients with confirmed COVID-19 were identified and only 106 (24.5\%) patients with moderate, severe or critical illness (mean age $55.6 \pm 13.2$ years old, $80.2 \%$ were male) were included in this study, of whom 34 (32\%) died during their hospitalisation. The main complications of the patients included ARDS in 59/66 (89.4\%) patients, coagulopathy in 35/93 (37.6\%) patients, acute cardiac injury in 24/98 (24.5\%) patients, AKI in 15/74 (20.3\%) patients and secondary infection in 12/81 (14.8\%) patients. The independent predictors of mortality were found to be age [aHR 1.38; 95\% Cl 1.10-1.82], AKI stage 3 [aHR 2.51; 95\% Cl 1.33-6.80], proteinuria [aHR 2.60; 95\% Cl 1.40-6.42], respiratory rate [aHR 1.42; 95\% Cl 1.09-1.92] and procalcitonin [aHR 1.08; 95\% Cl 1.03-1.14]. The median survival time of the entire group was 12 days. The cumulative survival rate of COVID-19 patients was $86.9 \%, 65.0 \%$ and $19.9 \%$ respectively at 5,10 and 20 days. Levels of creatinine $(p=0.012)$, were clearly elevated in non-survivors compared with survivors throughout the clinical course and increased deterioration.

Conclusion: Mortality rate of COVID-19 patients is high, particularly in intubated patients and is associated with age, respiratory rate, proteinuria, procalcitonin and acute kidney injury.

\footnotetext{
*Correspondence: yannicknlandu@yahoo.fr

1 Intensive Care Unit, Kinshasa Medical Center, Kinshasa, Democratic

Republic of the Congo

Full list of author information is available at the end of the article
}

(C) The Author(s) 2021. Open Access This article is licensed under a Creative Commons Attribution 4.0 International License, which permits use, sharing, adaptation, distribution and reproduction in any medium or format, as long as you give appropriate credit to the original author(s) and the source, provide a link to the Creative Commons licence, and indicate if changes were made. The images or other third party material in this article are included in the article's Creative Commons licence, unless indicated otherwise in a credit line to the material. If material is not included in the article's Creative Commons licence and your intended use is not permitted by statutory regulation or exceeds the permitted use, you will need to obtain permission directly from the copyright holder. To view a copy of this licence, visit http://creativecommons.org/licenses/by/4.0/. The Creative Commons Public Domain Dedication waiver (http://creativeco mmons.org/publicdomain/zero/1.0/) applies to the data made available in this article, unless otherwise stated in a credit line to the data. 
Keywords: COVID-19, Mortality, African people, Procalcitonin, Acute kidney injury

\section{Background}

In December 2019, the first case of coronavirus disease 2019 (COVID-19), caused by the severe acute respiratory syndrome coronavirus 2 (SARS-COV-2) was detected in China [1]. Three months later, due to its rapid global spread, the World Health Organization (WHO) declared the outbreak a pandemic [1]. By the end of September 2020, the WHO had reported that SARS-COV-2 had infected at least 32.7 million people and was responsible for the deaths of more than one million [2]. The clinical manifestations of this new disease vary widely in severity; ranging from no or mild symptoms to patients with pneumonia progressing rapidly to acute respiratory distress syndrome (ARDS), multi-organ failure and death [3]. There is not only a huge disparity in the severity of this disease but also in its impact globally. From the onset of the pandemic, WHO predicted high morbidity and mortality rates in African countries. However, this has not transpired, with Africa reporting much lower rates than most of the rest of the world [4-6]. Notwithstanding the huge amount of global research investigating these morbidity and mortality disparities, most of these data emanate from non-African countries.

The Democratic Republic of Congo (DRC) situated in Central Africa, is a vast country with a surface area equivalent to Western Europe with an population of $89,561,403$ [4]. The country reported its first case of COVID-19 on March 10, 2020. This was an imported case from France [7]. As of September 27, 2020, there have been a total of 10,592 positive cases, with a mortality of 271 [2]. To date there is a paucity of research on COVID-19 from the DRC, two papers have been identified. The objective of this study was to identify the factors/determinants for COVID-19 related mortality by comparing the demographic and clinical characteristics of patients diagnosed with COVID-19 admitted to the Kinshasa Medical Center (KMC), located in Kinshasa, the capital of the Democratic Republic of Congo (DRC).

\section{Methods}

\section{Study design, setting and population}

This retrospective, observational, cohort study was carried out at the KMC, a private hospital officially designated for the treatment of COVID-19 between March 10, 2020 and July 10, 2020. The sampling for this study was consecutive. The inclusion criteria were strictly based on laboratory confirmation of SARS-CoV-2 by qualitative reverse-transcriptase polymerase chain reaction
(RT-PCR) assay of nasopharyngeal swabs. Only patients who demonstrated signs of moderate, severe and critical illness were admitted to hospital. There was no formal determination of sample size and all patients meeting the inclusion criteria were recruited.

\section{Ethics approval}

This study was carried out in strict compliance with the recommendations of the Declaration of Helsinki III [8]. The data were collected anonymously and confidentially. The information obtained during the history and clinical examination was transcribed into pre-established and pre-coded investigation sheets while respecting the confidentiality and privacy of patients. Our research projects on Covid-19 had been authorized by the National Ethics committee of Health, Democratic Republic of Congo ( $\left.\mathrm{N}^{\circ} 225 / \mathrm{CNES} / \mathrm{BN} / \mathrm{PMMF} / 2020\right)$. The need for ethics approval and consent to participate were waived by the National Ethics committee of Health, Democratic Republic of Congo because of the urgency and unprecedented nature of the COVID-19 pandemic. Administrative permissions to access the raw data were granted by the Kinshasa Medical Center (KMC) direction.

\section{Data collection}

Clinical data were extracted manually from the $\mathrm{KMC}$ electronic patient database. Information about demographic characteristics (age and gender); the existence of any chronic conditions (hypertension, diabetes mellitus, chronic kidney disease);initial symptoms (fever, cough, shortness of breath, chills, dyspnea, fatigue, nausea, vomiting, and diarrhea); vital signs (temperature, respiratory rate $[R R]$, heart rate $[H R]$, and blood oxygen saturation $[\mathrm{BOS}]$ ); and laboratory tests (haemoglobin $[\mathrm{Hb}]$, white blood cells [WBC], neutrophils, lymphocytes, platelets, albumin, creatinine, urea, lactate dehydrogenase [LDH], creatine kinase [CK], D-dimer, C-reactive protein [CRP], procalcitonin $[\mathrm{PCT}]$, fibrinogen, high sensitivity Troponin I [hsTNI], electrolytes) and thoracic computerized tomography scan $(\mathrm{CT})$ score were all collected from the time of the admission except for CRP, procalcitonin and creatinine which were repeated systematically on day 1 , 3 and 7 in according to the hospital protocol. In addition, we collected information about the treatment received (administration of antibiotics, corticosteroids, oxygen therapy, mechanical ventilation or haemodialysis, complications, and outcomes during the hospital admission. Blood parameters were categorized according to normal reference ranges used in hospital. 


\section{Definitions}

Fever was defined as axillary temperature of at least $37 \cdot 3{ }^{\circ} \mathrm{C}$. Hypertension was recorded if the patient was taking any antihypertensive drug or had two separate BP measurements $\geq 140 / 90 \mathrm{mmHg}$ [9]. Secondary infection was diagnosed when patients showed clinical symptoms or signs of pneumonia or bacteraemia and a positive culture of a new pathogen was obtained from blood samples after admission [10]. The diabetes diagnosis was based on criteria from the American Diabetes Association as a presence of a fasting plasma glucose level of $>126 \mathrm{mg} /$ $\mathrm{dL}$ or usage of antidiabetic drug [11]. CKD was defined according to KDIGO definition [12]. ARDS was defined according to the Berlin Definition [13]. Acute Kidney Injury (AKI) was diagnosed according to KDIGO clinical practice guidelines based on the serum creatinine levels [14]. Acute cardiac injury was diagnosed if the serum concentration of HsTNI was above the upper limit of the reference range $(>28 \mathrm{pg} / \mathrm{mL})$ [15]. Coagulopathy was defined as a prothrombin time ratio (PTr) of less than $70 \%[16]$.

On admission each patient had a thoracic CT scan that was assessed for severity of pulmonary involvement. A semi-quantitative CT scoring system was calculated based on the extent of lobar involvement $(0: 0 \% ; 1:<5 \%$; 2:5-25\%; 3:26-50\%; 4:51-75\%; 5: > 76\% [17].

\section{Statistical analysis}

The data was entered and encoded using the Epi info 3.5 software. Data analyzes were performed using SPSS version 21 software. Descriptive statistics consisted of calculating the mean and standard deviation for quantitative data with Gaussian distribution; the median and interquartile range (IQR) for quantitative data with non-Gaussian distribution. Proportions were used for categorical data and percentage are based on the total number of non-missing value.

Pearson's Chi-square test or Fisher's exact test was used to compare the proportions. For continuous variables, the comparisons between the survivor and non-survivor groups were made using student's t-test (variables normally distributed) or Mann Whitney's test (variables not normally distributed). Kaplan Meier's method was used to describe the survival between the date of admission in KMC care and death (complete data) and the end of the study (censored data). The Log-rank test was used to compare survival curves. Factors associated with mortality in unadjusted univariable cox regression were included in a multivariable cox regression model to identify independent factors associated with mortality, the Odd ratio (OR) was calculated for each independent variable. We excluded variables from the univariable analysis if their between-group differences were not significant, if the number of events was too small to calculate odds ratios. Only significant variables in univariable cox regression were retained in the final model. A p value $<0.05$ was considered the threshold of statistical significance.

\section{Results}

Of 432 consecutive patients with COVID-19 who were admitted to the Hospital Emergency Department at KMC between March 10, 2020 and July 10, 2020, only 106 were hospitalized and followed during the study period (Fig. 1). The baseline characteristics of these 106 patients are summarised in Table 1 and their laboratory findings and chest CT scan score in Table 2. 34 patients died during hospitalisation and 72 were discharged. The mean age of the admitted patients was $55.6 \pm 13.2$ years, including $26(24.5 \%)$ patients over 65 years old. The majority were male $(80.2 \%)$ with hypertension being the main comorbidity in $62(58.2 \%)$ patients. The median (IQR) time from COVID-19 symptoms onset to hospital admission was 7 (5.8-10.0) days, whereas the median time to death was 22.0 (14.0-33.0). Fever and cough were the most common initial symptoms $(65.1 \%$ and $55.7 \%$, respectively). On admission, the median axillary temperature was $37.1{ }^{\circ} \mathrm{C}$ (IQR: $36.6-38.3{ }^{\circ} \mathrm{C}$ ). The median respiratory rate was 22/min (IQR: $20-29 / \mathrm{min}$ ) and median blood oxygen saturation on room air was 89\% (IQR: 82-92\%). Compared between the two groups, the patients in non-survivors group had significantly higher age $(61.3 \pm 12$ vs $52.9 \pm 13)$, Systolic Blood Pressure $(145.5 \pm 17.4$ vs $137.0 \pm 17)$, Lactate dehydrogenase (604 [244-874.8] vs 362.5 [228.3-551.8]), HDL cholesterol (1.19 [0.75-1.55] vs 0.85 [0.66-1.08]), troponin (20.8 [10.3-90.5] vs 4.9 [2.0-16.9]), procalcitonin $(0.360$ [0.185-2.583] vs $0.140[0.06-0.440])$ and lower $\mathrm{PaO} 2 /$ FiO2 ratio (67.6 [57.9-96.5] vs $145.5 f$ [73.1-251.2]). The patients in non-survivors group had also significantly more count of neutrophil (5120.5 [3748-7815] vs 3555.7 [2630-5911.5]) (Table 2). The frequency of complications was higher in non-survivors than survivors (Table 3). The main Complications of the patients included ARDS in $59 / 66(89.4 \%)$ patients, coagulopathy in 35/93 (37.6\%) patients, acute cardiac injury in $24 / 98$ (24.5\%) patients, AKI in 15/74 (20.3\%) patients and secondary infection in $12 / 81(14.8 \%)$ patients (Table 3$)$. Only 24 patients were on corticosteroids. All $28(26.4 \%)$ patients who required mechanical ventilation (MV) died. The median time from illness onset to invasive mechanical ventilation was 15 days (9.0-22.0). 14 (13.2\%) patients received renal replacement therapy. Some laboratory parameters were tracked from illness onset (Fig. 1). Levels of CRP, PCT and creatinine were clearly elevated in non-survivors 


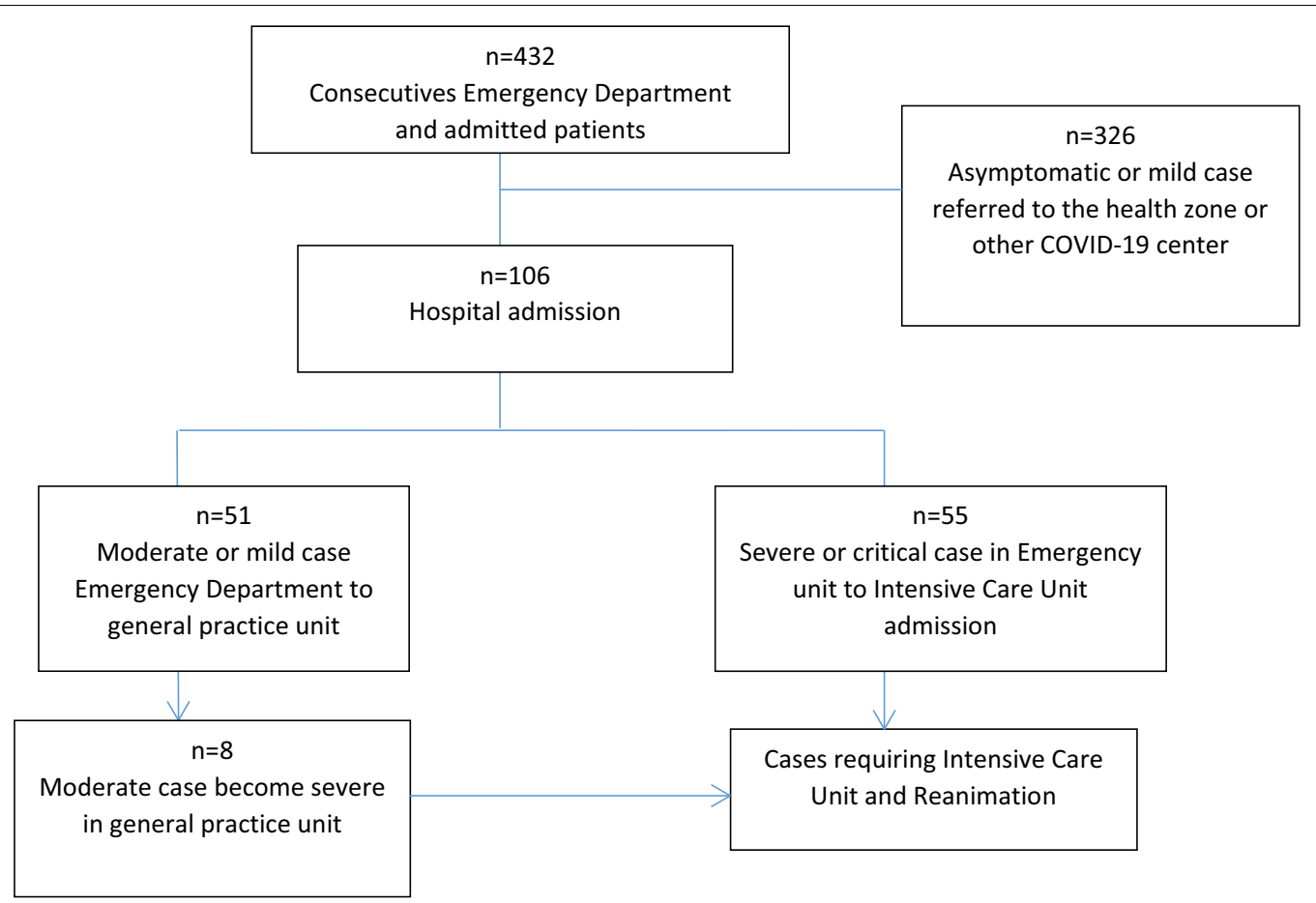

Fig. 1 Flow chart of study population selection

Table 1 Clinical features at admission

\begin{tabular}{|c|c|c|c|c|}
\hline & Total $(n=106)$ & Non-survivors $(n=34)$ & Survivors $(n=72)$ & p-value \\
\hline Age, years & $55.6 \pm 13.2$ & $61.3 \pm 12.0$ & $52.9 \pm 13.0$ & 0.002 \\
\hline$>65$ years & $26(24.5)$ & $15(44.1)$ & $11(15.3)$ & 0.001 \\
\hline \multicolumn{5}{|l|}{ Sex } \\
\hline Females & 21(19.8) & $6(17.6)$ & $15(20.8)$ & \multirow[t]{2}{*}{0.701} \\
\hline Males & $85(80.2)$ & $28(82.4)$ & $57(79.2)$ & \\
\hline \multicolumn{5}{|l|}{ Comorbidities } \\
\hline Hypertension & $62(58.5)$ & $21(61.8)$ & $41(56.9)$ & 0.638 \\
\hline Diabetes melitus & 35(33.0) & $14(41.2)$ & $21(29.2)$ & 0.220 \\
\hline CKD & $5(4.7)$ & $2(5.9)$ & $3(4.2)$ & 0.697 \\
\hline $\mathrm{SBP}, \mathrm{mm} \mathrm{Hg}$ & $139.8 \pm 17.5$ & $145.5 \pm 17.4$ & $137.0 \pm 17.0$ & 0.036 \\
\hline DBP, mm Hg & $84.9 \pm 13.9$ & $87.0 \pm 17.6$ & $83.8 \pm 11.7$ & 0.327 \\
\hline $\mathrm{HR}$, bpm & $92.1 \pm 15.1$ & $93.6 \pm 17.5$ & $91.3 \pm 14.0$ & 0.513 \\
\hline RR, cycle/min & $22.0(20.0-29.0)$ & $27.5(22.0-35.0)$ & $20.0(20.0-26.0)$ & 0.002 \\
\hline RR $>24$ cycles/min & $26(36.6)$ & $14(58.3)$ & $12(25.5)$ & 0.007 \\
\hline $\mathrm{T},{ }^{\circ} \mathrm{C}$ & $37.1(36.6-38.3)$ & $37.5(36.6-38.5)$ & $37.0(36.6-38.0)$ & 0.178 \\
\hline Fever & $69(65.1)$ & $22(64.7)$ & $47(65.3)$ & 0.954 \\
\hline Cough & $59(55.7)$ & $22(64.7)$ & $37(51.4)$ & 0.198 \\
\hline Dyspnea & $42(39.6)$ & $14(41.2)$ & $28(38.9)$ & 0.822 \\
\hline Asthenia & $42(39.6)$ & $11(32.4)$ & $31(43.1)$ & 0.293 \\
\hline Symptoms, days & $7.0(5.8-10.0)$ & $7.0(5.0-10.0)$ & $7.0(6.0-8.5)$ & 0.682 \\
\hline
\end{tabular}

Data are mean \pm standard, median (IQR), $\mathrm{n}(\%)$, or $\mathrm{n} / \mathrm{N}(\%)$. p values were calculated by Mann-Whitney $\mathrm{U}$ test, $\mathrm{X}^{2}$ test, or Fisher's exact test, as appropriate. Bpm beats per minutes, $C K D$ chronic kidney disease, $D B P$ diastolic blood pressure, $H R$ heart rate, $R R$ respiratory rate. $x^{2}$ test comparing all subcategories 
Table 2 Biological and radiological characteristics at admission

\begin{tabular}{|c|c|c|c|c|}
\hline Variable & Total $(n=106)$ & Non-survivors $(n=34)$ & Survivors $(n=72)$ & p-value \\
\hline Glycemia, mg/dl & $124.0(103.0-176.0)$ & $136.5(100.5-180.8)$ & $119.0(103.5-171.0)$ & 0.614 \\
\hline WBC count,$\times 10^{3} / \mathrm{I}$ & $6.2(4.8-8.7)$ & $7.0(5.3-9.96)$ & $5.9(4.5-8.1)$ & 0.056 \\
\hline$<4.0$ & $10(11.0)$ & $2(7.4)$ & $8(12.5)$ & 0.617 \\
\hline $4.0-10.0$ & $80(87.9)$ & $25(92.6)$ & $55(85.9)$ & \\
\hline$>10.0$ & $1(1.1)$ & $0(0)$ & $1(1.6)$ & \\
\hline Neutrophils count, $\times 10^{3} / 1$ & $4.3(2.92-6.38)$ & $5.12(3.75-7.82)$ & $3.56(2.63-5.91)$ & 0.021 \\
\hline Lymphocytes count, $\times 10^{3} / \mathrm{I}$ & $1.4(1.01-1.65)$ & $1.22(0.88-1.63)$ & $1.38(1.07-1.69)$ & 0.193 \\
\hline$<800$ & 13/103 (12.6) & $7 / 33(21.2)$ & 6/70 (8.6) & 0.071 \\
\hline Missing & 3 & 1 & 2 & - \\
\hline $\mathrm{Hb}, \mathrm{g} / \mathrm{dl}$ & $13.2 \pm 2.1$ & $12.9 \pm 2.2$ & $13.3 \pm 2.0$ & 0.372 \\
\hline ASAT, UI/I & $52.0(28.8-90.3)$ & $68.0(39.5-95.0)$ & $50.5(26.3-86.0)$ & 0.124 \\
\hline ALAT, UI/I & $35.5(24.8-68.3)$ & $32.5(24.8-62.8)$ & $39.5(23.5-73.0)$ & 0.712 \\
\hline ALAT > 40 UI & $48(45.3)$ & $13(38.2)$ & $35(48.6)$ & 0.316 \\
\hline Total Bilirubin, $\mu \mathrm{mol} / \mathrm{l}$ & $8.0(6.2-12.0)$ & $10.4(6.2-14.2)$ & $7.7(5.9-10.7)$ & 0.123 \\
\hline Direct Bilirubin, $\mu \mathrm{mol} / \mathrm{l}$ & $4.3(3.0-6.1)$ & $5.7(3.2-7.7)$ & $3.8(2.9-5.8)$ & 0.059 \\
\hline Pro BNP, pg/ml & 119.5 (45.0-633.8) & $279.5(47.3-1355.3)$ & $98.0(38.3-378.3)$ & 0.028 \\
\hline Ferritin, ng/ml & $1200.0(565.4-1200.0)$ & $1200.0(842.5-1200.0)$ & $1200.0(527.1-1200.0)$ & 0.377 \\
\hline $\mathrm{Na}^{+}, \mathrm{mmol} / \mathrm{l}$ & $137.9 \pm 4.4$ & $137.6 \pm 5.8$ & $138.1 \pm 3.7$ & 0.593 \\
\hline $\mathrm{K}^{+}, \mathrm{mmol} / \mathrm{l}$ & $3.8 \pm 0.5$ & $3.8 \pm 0.5$ & $3.8 \pm 0.4$ & 0.934 \\
\hline $\mathrm{HbA} 1 \mathrm{c}, \%$ & $8.3 \pm 2.7$ & $8.1 \pm 2.7$ & $8.4 \pm 2.8$ & 0.737 \\
\hline Creatinin, $\mu \mathrm{mol} / \mathrm{l}$ & $89.5(74.0-110.3)$ & $100.5(74.8-125.5)$ & $85.5(74.0-105.3)$ & 0.164 \\
\hline LDH, UI/I & $410.0(232.0-656.3)$ & $604.0(244.0-874.8)$ & $362.5(228.3-551.8)$ & 0.026 \\
\hline$>245$ & 68/98 (69.4) & 23/30 (76.7) & 45/68(66.2) & 0.299 \\
\hline Missing & 8 & 3 & 5 & - \\
\hline CK, UI/I & 199.0 (96.0-398.0) & $274.0(99.5-485.8)$ & $163.0(93.0-354.0)$ & 0.214 \\
\hline$>185$ & $46 / 91(50.5)$ & 18/28 (64.3) & 28/63 (44.4) & 0.081 \\
\hline Missing & 15 & 5 & 10 & - \\
\hline $\mathrm{TC}, \mathrm{mmol} / \mathrm{l}$ & $4.2(3.3-5.6)$ & $4.2(3.3-5.7)$ & $4.3(3.2-5.5)$ & 0.927 \\
\hline HDLc, mmol/l & $0.93(0.67-1.24)$ & $1.19(0.75-1.55)$ & $0.85(0.66-1.08)$ & 0.047 \\
\hline Triglycerids, mmol/l & $1.40(0.94-2.19)$ & $1.51(0.79-2.15)$ & $1.36(1.09-2.38)$ & 0.430 \\
\hline Troponin, ng/l & $9.9(3.2-27.9)$ & $20.8(10.3-90.5)$ & $4.9(2.0-16.9)$ & $<0.0001$ \\
\hline$>28$ & $24(24.5)$ & $14(41.2)$ & $10(15.6)$ & 0.005 \\
\hline $\mathrm{PTr}, \%$ & $74.3 \pm 16.6$ & $75.4 \pm 17.0$ & $73.8 \pm 16.6$ & 0.674 \\
\hline$<70$ & 35/93 (37.6) & 11/28 (39.3) & 24/65 (36.9) & 0.829 \\
\hline$\geq 70$ & $58 / 93(62.4)$ & $17 / 28(60.7)$ & $41 / 65(63.1)$ & - \\
\hline Missing & 13 & 3 & 10 & - \\
\hline D-dimer, ng/ml & $1603.5(795.3-4093.3)$ & $1694.2(921.6-5482.1)$ & $1593.3(744.5-3329.7)$ & 0.430 \\
\hline$\leq 500$ & $14 / 97(14.4)$ & $5 / 31(16.1)$ & 9/66 (13.6) & 0.305 \\
\hline$>500-\leq 1000$ & 18/97 (18.6) & 3/31 (9.7) & 15/66 (22.7) & - \\
\hline$>1000$ & 65/97 (67.0) & 23/31 (74.2) & 42/66 (63.6) & - \\
\hline Missing & 9 & 2 & 7 & - \\
\hline Fibrinogen, g/l & $7.3(5.4-8.4)$ & $7.4(6.3-9.1)$ & $7.2(5.2-8.2)$ & 0.254 \\
\hline CRP, mg/l & $125.0(53.0-218.0)$ & $209.5(107.0-309.3)$ & $95.5(29.5-187.8)$ & $<0.0001$ \\
\hline $\mathrm{PCT}, \mathrm{ng} / \mathrm{ml}$ & $0.200(0.095-0.620)$ & $0.360(0.185-2.503)$ & $0.140(0.060-0.440)$ & $<0.0001$ \\
\hline$<0.1$ & $26(24.8)$ & $1(2.9)$ & $25(35.2)$ & 0.002 \\
\hline $0.1-<0.25$ & $30(28.6)$ & $11(32.4)$ & $19(26.8)$ & \\
\hline $0.25-<0.5$ & $18(17.1)$ & $6(17.6)$ & $12(16.9)$ & \\
\hline$\geq 0.5$ & $31(29.5)$ & $16(47.1)$ & $15(21.1)$ & \\
\hline $\mathrm{PaO} 2 / \mathrm{FiO} 2$ & $100.2(63.2-209.4)$ & $67.6(57.9-96.5)$ & $145.5(73.1-251.2)$ & 0.001 \\
\hline
\end{tabular}


Table 2 (continued)

\begin{tabular}{clll}
\hline Variable & Total $(\mathbf{n}=\mathbf{1 0 6})$ & Non-survivors $(\mathbf{n}=\mathbf{3 4 )}$ & Survivors $(\mathbf{n}=\mathbf{7 2})$ \\
\hline TDM Score & & & \\
Normal & $3 / 92(3.3)$ & $0 / 27(0.0)$ & $3 / 65(4.6)$ \\
Score 1 & $11 / 92(12.0)$ & $0 / 27(0.0)$ & $11 / 65(16.9)$ \\
Score 2 & $3 / 27(11.1)$ & $14 / 65(21.5)$ \\
Score 3 & $17 / 92(18.5)$ & $4 / 27(14.8)$ & $23 / 65(35.4)$ \\
Score 4 & $27 / 92(29.3)$ & $11 / 27(40.7)$ & $11 / 65(16.9)$ \\
Score 5 & $22 / 92(23.9)$ & $9 / 27(33.3)$ & $3 / 65(4.6)$ \\
Missing & $12 / 92(13.0)$ & 5 & 9 \\
\hline
\end{tabular}

Data are mean \pm standard, median (IQR), $\mathrm{n}(\%)$, or $\mathrm{n} / \mathrm{N}(\%)$. Percentage are based on the total number of non-missing values in each category and not necessarily on the total number of participants. P values were calculated by Mann-Whitney $\mathrm{U}$ test, $\mathrm{X}^{2}$ test, or Fisher's exact test, as appropriate. ALAT Alanina Amino Transferase, ASAT aspartate amino transferase, $C R P C$ reactive protein, $H b$ haemoglobin, $H D L C$ high density Lipoprotein cholesterol, $L D H$ lactate dehydrogenase, $C K$ creatinine kinase, Pro $B N P$ brain natriuretic peptide, PTR prothrombine time ratio, PCT Procalcitonin, TC total cholesterol, WBC white blood cell

Table 3 Patients management and evolution

\begin{tabular}{|c|c|c|c|c|}
\hline Variable & Total $(n=106)$ & Non-survivors $(n=34)$ & Survivors $(n=72)$ & $\mathrm{p}$-value \\
\hline \multicolumn{5}{|l|}{ Oxygen therapy at admission } \\
\hline Ambient air & $10(9.5)$ & $0(0)$ & $10(14.1)$ & \multirow[t]{4}{*}{$<0.0001$} \\
\hline Nasal cannula oxygenotherapy & $18(17.1)$ & $2(5.9)$ & $16(22.5)$ & \\
\hline High concentration oxgen masks & $68(64.8)$ & $24(70.6)$ & $44(62.0)$ & \\
\hline Non invasive ventilation & $9(8.6)$ & $8(23.5)$ & $1(1.4)$ & \\
\hline \multicolumn{5}{|l|}{ ARDS severity } \\
\hline No ARDS & $7 / 66(10.6)$ & $0 / 24(0.0)$ & $7 / 42(16.7)$ & \multirow[t]{5}{*}{0.003} \\
\hline Mild ARDS & $11 / 66(16.7)$ & $2 / 24(8.3)$ & $9 / 42(21.4)$ & \\
\hline Moderate ARDS & $15 / 66(22.7)$ & $3 / 24(12.5)$ & $12 / 42(28.6)$ & \\
\hline Severe ARDS & $33 / 66(50.0)$ & $19 / 24(79.2)$ & $14 / 42(33.3)$ & \\
\hline Missing & 40 & 16 & 24 & \\
\hline AKI & 15/74 (20.3) & $12 / 30(40.0)$ & $3 / 44(6.8)$ & $<0.0001$ \\
\hline Missing & 32 & 14 & 18 & \\
\hline Hemodialysis & $14(13.2)$ & $13(38.2)$ & $1(1.4)$ & $<0.0001$ \\
\hline ARDS & $59 / 66(89.4)$ & $24 / 24(100)$ & $35 / 42(83.3)$ & 0.034 \\
\hline Missing & 40 & 16 & 24 & \\
\hline Mechanical ventilation & $28(26.4)$ & $28(82.3)$ & $0(0.0)$ & - \\
\hline Vasopressors use & $9(10)$ & $9(32.1)$ & $0(0.0)$ & - \\
\hline \multicolumn{5}{|l|}{ Delay from symptoms onset to } \\
\hline Corticosteroids start, day & $10.0(7.0-15.0)$ & $11.0(8.0-13.0)$ & $10.0(6.0-15.0)$ & 0.495 \\
\hline NIV initiation, day & $12.0(7.0-13.0)$ & $12.0(7.0-13.0)$ & - & - \\
\hline Mechanical Ventilation initiation, day & $15.0(9.0-22.0)$ & $15.0(9.0-22.0)$ & - & - \\
\hline Death or discharge, day & $19.0(15.0-26.0)$ & $22.0(14.0-33.0)$ & $18.0(15.0-22.0)$ & 0.113 \\
\hline
\end{tabular}

Data are median (IQR), $\mathrm{n}(\%)$, or $\mathrm{n} / \mathrm{N}(\%)$. Percentage are based on the total number of non-missing values in each category and not necessarily on the total number of participants. $P$ values were calculated by Mann-Whitney $U$ test, $\mathrm{X}^{2}$ test, or Fisher's exact test, as appropriate. AKI acute kidney injury, ARDS acute respiratory distress syndrome, NIV non-invasive ventilation

compared with survivors throughout the clinical course (Fig. 2). As of July 10, 2020, $34(32.0 \%)$ patients had died; of those that died a total of $17.6 \%(6 / 34)$ had secondary infections. The main bacterial infection found were Staphylococus haemolyticus (Fig. 3). The median (IQR) length of stay from hospitalization to discharge was $18(15-22)$ days, while the median (IQR) time from hospitalization to death was 22 (14-33) days. Kaplan Meir survival curve of the study population is illustrated in Fig. 4. The median survival time of the entire group was 12 days. The cumulative survival rate of COVID-19 patients was $86.9 \%, 65.0 \%$ and $19.9 \%$ respectively at 5 , 10 and 20 days. The Kaplan-Meir curves showed a better survival in younger patients, in patients with No AKI 


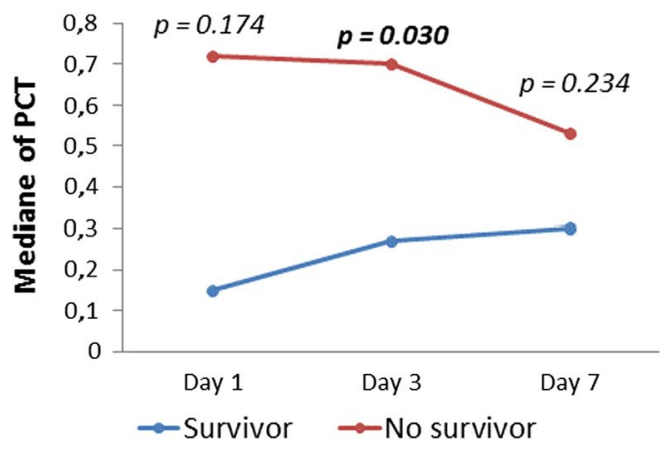

A

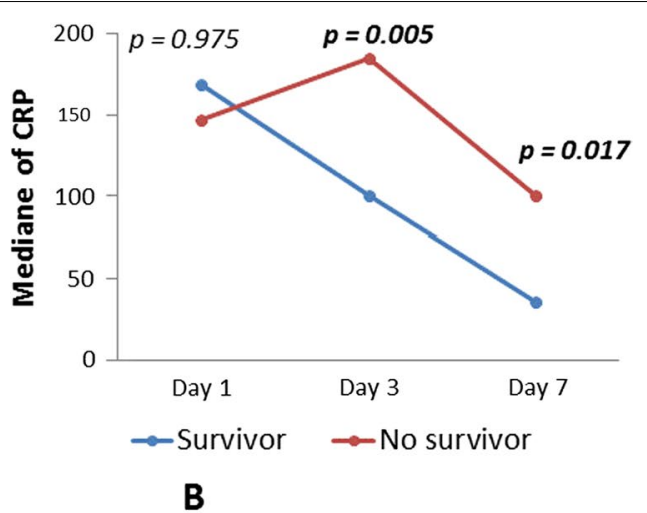

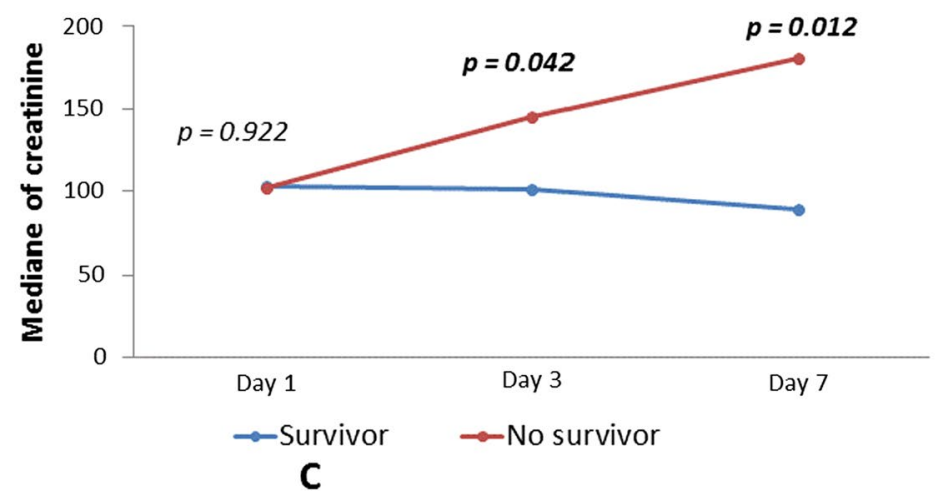

Fig. 2 Temporal changes in laboratory markers from illness onset in patients hospitalised with COVID-19 Figure shows temporal changes in Procalcitonin (A), C-reactive protein (B) and creatinin (C). Differences between survivors and non-survivors were significant for all time points shown

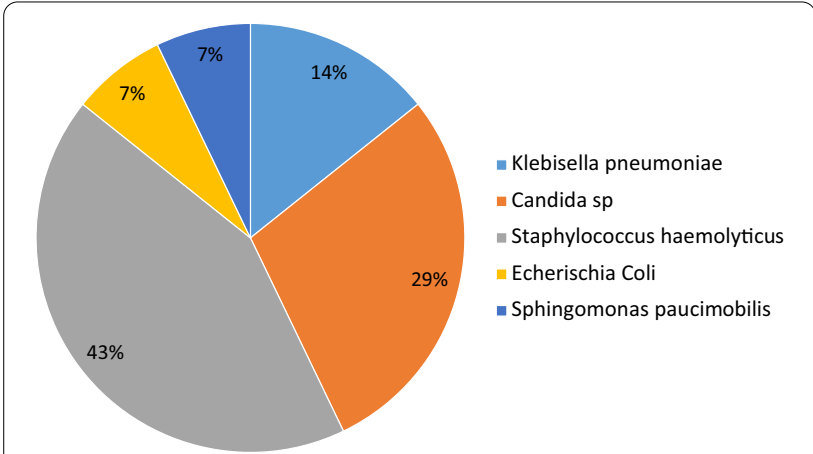

Fig. 3 Diagram of main secondary infection in COVID-19 patients

and in patients who have a procalcitonin level below 0.5 . Patients with no proteinuria and lower respiratory rate at presentation have also a better survival (Fig. 5). Multivariable analysis (Table 4) showed age [aHR 1.38; $95 \%$ CI 1.10-1.82], AKI stage 3 [aHR 2.51; 95\% CI 1.33-6.80], proteinuria [aHR 2.60; 95\% CI 1.40-6.42], RR [aHR 1.42; 95\% CI 1.09-1.92] and procalcitonin [aHR 1.08; 95\% CI 1.03-1.14] as factors independently associated with an increased risk of mortality.

\section{Discussion}

To date, only two studies have been published from the DRC examining patients admitted with COVID-19 [17, 18]. Both these studies were limited by a lack of robust analysis of biological and laboratory parameters that might predict hospital mortality in COVID-19 [7, 18]. Our retrospective cohort study, carried out in the DRC, aims to add comprehensive data about mortality risk factors for COVID-19. The findings demonstrate that age, respiratory rate, proteinuria, procalcitonin and AKI were significantly associated with mortality in COVID-19 patients. Additionally, increasing levels of creatinine during hospital admission were associated with an increased mortality.

Globally, the hospital COVID-19 mortality rates varies between 4 and $70 \%$ [19-25]. This disparity is partially explained by differences in the epidemiology of the study populations as well as in their hospital management. For example, Du et al. demonstrated that older patients with pre-existent co-morbidities had a higher risk of mortality than a younger healthier person [25]. Ciceri et al. reported $23 \%$ mortality in patients presenting less severe forms on admission (a median oxygen saturation of 93\%) [26]. In comparison, our study revealed a mortality of 


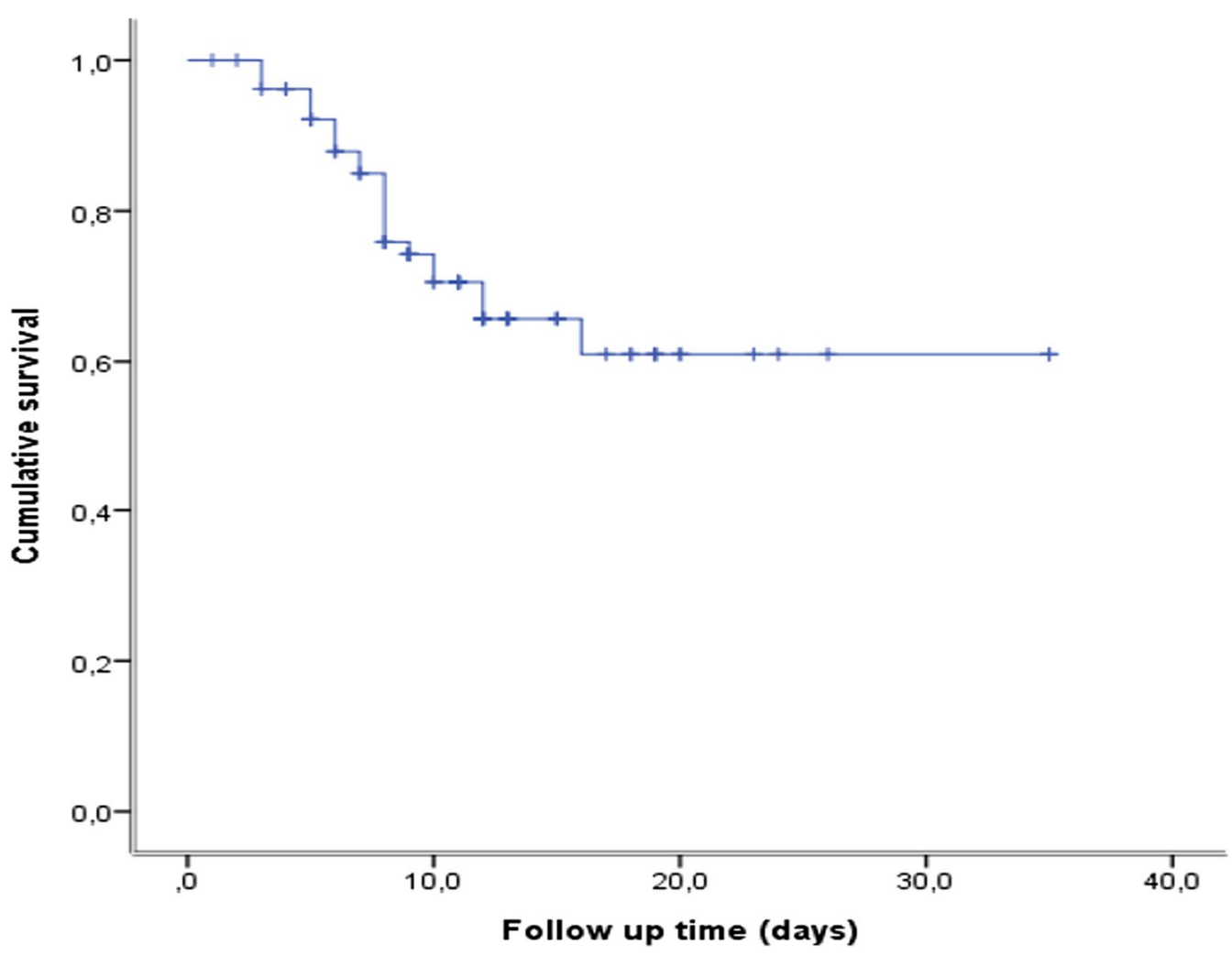

Fig. 4 Survival Curve of COVID-19 patients study population

$32.0 \%$ of whom only $24.5 \%$ had an age $>65$ years, and had few comorbidities and upon admission had a less severe form of the disease (mean $\mathrm{PaO} 262.62 \pm 14.0 \mathrm{mmHg}$ ). In contrast to international studies demonstrating that being male is associated with an increased risk of mortality [27], our findings did not demonstrate any significant gender difference in risk. All intubated patients died, reflecting the difficulty to manage mechanical ventilation of COVID-19 patients during the first wave in the context of lack of experience and clear recommendations.

As in several previous studies [25-29], in our study an advanced age was associated with increased mortality from COVID-19. This vulnerability amongst the elderly is often explained by immunoscenescence that is accompanied by a decrease in the production of native $T$ and $B$ cells as well as a decrease in the function of immune cells participating in innate immunity [28]. These changes reduce the effective viral clearance and increase the likelihood of triggering a deregulated immune response in which cytokines are largely released from activated immune cells causing a cytokine storm [28]. In addition to immune senescence, there are several other agerelated factors such as comorbidities resulting in higher morbidity and mortality [28]. In our cohort, the number of comorbidities also increased with age.
Viral infections are not usually associated with a raised serum PCT, a finding supported in current COVID-19 research [30]. Procalcitonin, which is the 116-amino acid precursor of the hormone calcitonin, is normally synthetized and released by thyroid parafollicular C cells [30]. It can also be synthetized in many extrathyroid tissues during bacterial infection which is mediated by increased concentration of tumor necrosis factor alpha (TNF $\alpha)$ and interleukin 6 [30]. Worldwide, the average PCT level on admission is less than $0.25 \mu \mathrm{g} / \mathrm{L}$ in COVID-19 patients [31]. During admission for COVID-19, an increased PCT is explained either by a bacterial hospital acquired co-infection or by a general deterioration of the patient [32]. Several studies have reported that elevated PCT is positively associated with the severity of COVID-19 [10, 33-35]. Hu et al. describe bacterial co-infection rates, defined by a positive blood culture in $20 \%$ of those who were severely unwell and in 50\% who were critically unwell. Yet, in $50 \%$ of those with severe COVID-19 and in $80 \%$ of those critically unwell the PCT was raised [30]. In our study, $12 / 81$ (14.8\%) of admission blood cultures were positive yet the PCT was raised in $29.5 \%$ of those patients. Our study demonstrated that during infection with COVID-19 a progressive elevation of PCT served as a marker for a poor prognosis. This finding 


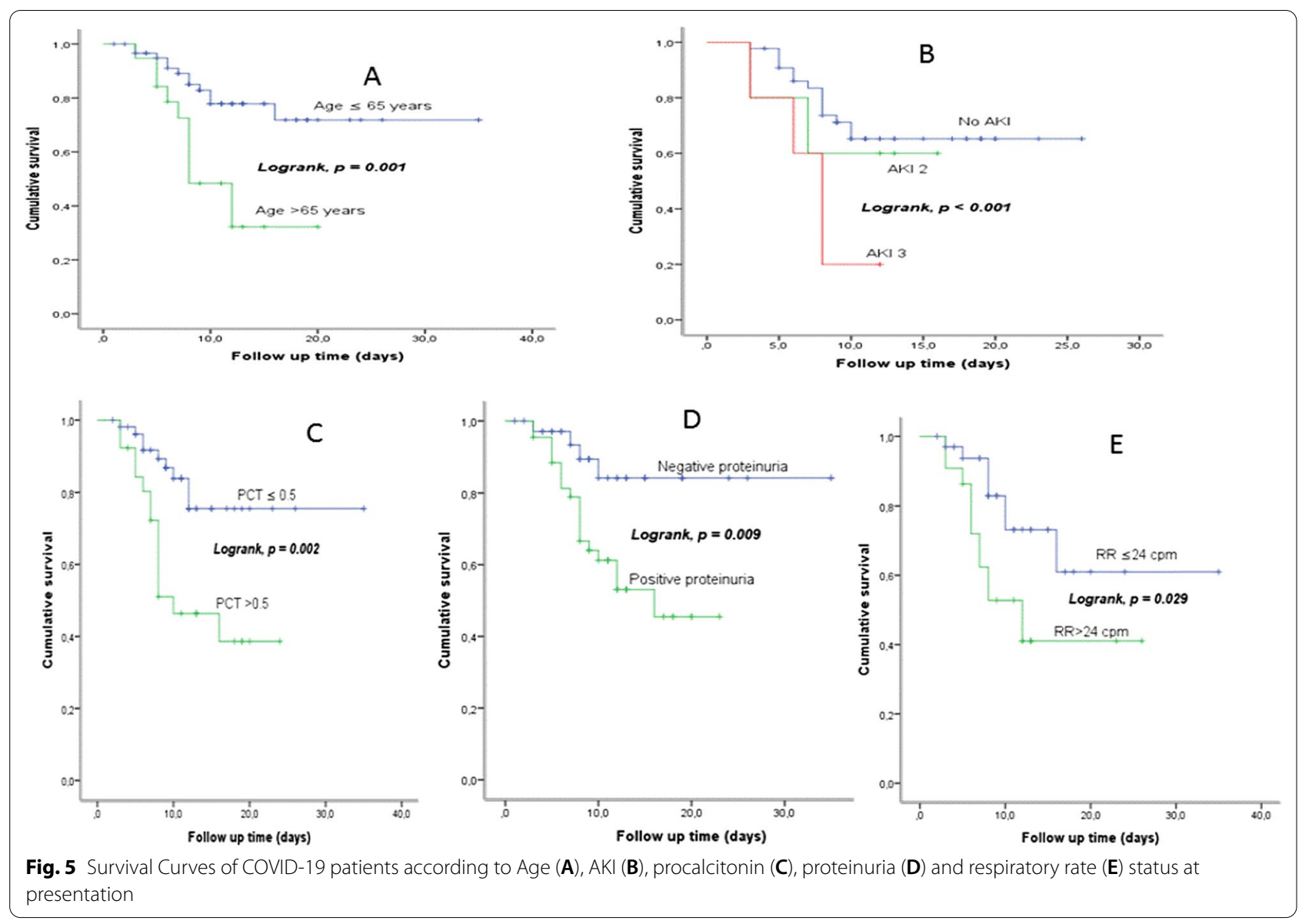

Table 4 Predictors of mortality in COVID-19 patients

\begin{tabular}{|c|c|c|c|c|}
\hline Variable & Unadjusted HR (95\% Cl) & $\mathrm{p}$ & Adjusted HR (95\% Cl) & $\mathrm{p}$ \\
\hline Age $^{*}$ & $1.05(1.02-1.09)$ & 0.005 & $1.38(1.10-1.82)$ & 0.018 \\
\hline \multicolumn{5}{|l|}{ Proteinuria } \\
\hline Negative & 1 & & 1 & \\
\hline Positive & $3.72(1.27-10.94)$ & 0.017 & $2.60(1.40-6.42)$ & 0.009 \\
\hline $\mathrm{RR}^{*}$ & $1.06(1.02-1.11)$ & 0.008 & $1.42(1.09-1.92)$ & 0.019 \\
\hline Troponin* & $1.03(10.1-10.5)$ & 0.001 & $1.79(0.35-9.10)$ & 0.481 \\
\hline CRP* & $1.04(1.01-1.07)$ & 0.007 & $1.03(0.99-1.07)$ & 0.288 \\
\hline \multicolumn{5}{|l|}{ AKI } \\
\hline No AKI & 1 & & 1 & \\
\hline AKI 2 & $2.61(0.86-7.97)$ & 0.091 & $0.91(0.26-3.26)$ & 0.890 \\
\hline AKI 3 & $4.47(1.59-12.58)$ & 0.005 & $2.51(1.33-6.80)$ & 0.016 \\
\hline PCT* & $1.09(1.04-1.14)$ & $<0.001$ & $1.08(1.03-1.14)$ & 0.002 \\
\hline ProBNP* & $1.09(0.75-1.86)$ & 0.285 & $1.19(0.20-1.36)$ & 0.288 \\
\hline $\mathrm{LDH}^{*}$ & $1.09(0.99-1.19)$ & 0.077 & $1.50(0.35-1.68)$ & 0.633 \\
\hline $\mathrm{PaO} 2 / \mathrm{FiO}^{*}$ & $1.43(0.99-1.99)$ & 0.636 & $1.10(0.98-1.98)$ & 0.284 \\
\hline $\mathrm{SBP}^{*}$ & $1.03(0.02-1.28)$ & 0.722 & $1.54(0.39-1.69)$ & 0.101 \\
\hline Neutrophils* & $1.03(0.20-1.43)$ & 0.070 & $1.00(0.301 .61)$ & 0.866 \\
\hline
\end{tabular}

Bold values are the statistically significant $\mathrm{p}$ defining the variables (factors) associated to mortality

$A K l$ acute kidney injury, $R R$ respiratory rate, $C R P C$-reactive protein, $P C T$ Procalcitonin, SBP systolic blood pressure, $H R$ hazard ratio *variables continues 
was supported by a study by Lippi et al. [36]. Unlike the increase in creatinine, procalcitonin decreases over time in non-survivors and can suggest that the worse outcome of COVID-19 patients in the study may be secondary to organ dysfunction and not superinfection.

Acute Kidney Injury (AKI) affects approximatively 20-40\% of COVID-19 patients admitted to intensive care [37]. It is considered as a marker of disease severity and a negative prognostic factor for survival $[37,38]$. AKI can lead to impaired acid-base, fluid, and electrolyte homeostasis, all of which may contribute to worse outcomes for patients with COVID-19 [38]. In our cohort the incidence of AKI was $16.2 \%$. A progressive elevation of creatinine was noted as a marker for poor prognosis, yet, only AKI stage 3 was found to be an independent risk factor associated with mortality. AKI is a well-recognised factor of poor prognosis but during the SARS Cov- 2 pandemic few studies have found a significant association between AKI and death [37]. This might be explained by the findings of Cheng et al. who demonstrated that only AKI Stages 2 or 3 are associated with a high risk of mortality [39]. Proteinuria is not only a marker for kidney disease or its progression, but also a manifestation of systemic disease in the kidney. Although transient, proteinuria is reported to be a disease severity marker and a mortality risk cause in Intensive care unit (ICU). As in previous studies $[40,41]$, proteinuria was associated with increased mortality in ICU COVID-19 patients.

\section{Strengths and limitations}

One of the principle weaknesses of this study is that it was carried out in a single centre thus the results cannot be generalised to all COVID-19 patients. Another weakness is that because it is retrospective we were unable to obtain all data related to the parameters of interest. This being a private hospital localized in the COVID-19 epicentre area and providing specialized tertiary care, can therefore likely to represent a selected group and lead to an overestimation of COVID-19 mortality. Finally, the small sample size was not sufficiently powered to identify potential associations between variables of interest. Nevertheless, this study has the advantage of being the first one in the DRC to examine epidemiological and laboratory data during the course of the admission to evaluate some of the risks factors associated with mortality among COVID-19 patients.

\section{Conclusion}

Mortality rate of COVID-19 patients is high, particularly in intubated patients and is associated with age, respiratory rate, procalcitonin, proteinuria and acute kidney injury.

\section{Abbreviations}

AKI: Acute kidney injury; ARDS: Acute respiratory distress syndrome ARDS; BOS: Blood oxygen saturation; CK: Creatinine kinase; CKD: Chronic kidney disease; CRP: C-reactive protein; CT: Computer tomography; Covid-19: Coronavirus disease 2019; DRC: Democratic Republic of Congo; FiO2: Inspired oxygen fraction; HB: Hemoglobin; HR: Heart rate; KMC: Kinshasa medical center; LDH: Lactate dehydrogenase; MV: Mechanical ventilation; PaO2: Arterial oxygen pressure; PCT: Procalcitonin; PTr: Prothrombin rate; RR: Respiratory rate; RT-PCR: Reverse transcriptase polymerase chain reaction; SARS-Cov-2: 2019 Novel coronavirus; WBC: White blood cell; WHO: World Health Organization.

\section{Acknowledgements}

The authors gratefully thank the staff of the Kinshasa Medical Center (KMC), for their commitment to the provision of excellent care to our patients.

\section{Authors' contributions}

YN and DM conceived and designed the study. DM and AN analysed data and performed statistical analysis. YN, AN, YE, MFM, JB and AR interpreted data. YN and MB drafted the manuscript. JS, JRN, JA, OT, PK, PB, JT, PA, JT, JPK, PM, MA, $J M M, R K, A S, K V E, C M, L B, D B, Y M$ and GK revised the manuscript. All authors approved the final submitted version for publication and have agreed to be accountable for all aspects of the work. All authors read and approved the final manuscript.

\section{Funding}

None.

\section{Availability of data and materials}

The datasets used and/or analysed during the current study are available from the corresponding author on reasonable request.

\section{Declarations}

\section{Ethical approval and consent to participate}

This study was carried out in strict compliance with the recommendations of the Declaration of Helsinki III [8]. The files were looked was designed anonymously. The information obtained during the history and clinical examination was transcribed into pre-established and pre-coded investigation sheets while respecting the confidentiality and privacy of patients. Our research projects on Covid-19 had been authorized by the National Ethics committee of Health, Democratic Republic of Congo ( $\left.N^{\circ} 225 / C N E S / B N / P M M F / 2020\right)$. The need for ethics approval and consent to participate were waived by the National Ethics committee of Health, Democratic Republic of Congo because of the urgency and unprecedented nature of the COVID-19 pandemic. Administrative permissions to access the raw data were granted by the Kinshasa Medical Center (KMC) direction.

\section{Consent for publication}

Not applicable.

\section{Competing interests}

The authors declare that the research was conducted in the absence of any commercial or financial relationships that could be considered as a potential conflict of interest.

\section{Author details}

${ }^{1}$ Intensive Care Unit, Kinshasa Medical Center, Kinshasa, Democratic Republic of the Congo. ${ }^{2}$ Nephrology Unit, Kinshasa University Hospital, Kinshasa, Democratic Republic of the Congo. ${ }^{3}$ Faculty of Public Health, Lomo University, Kinshasa, Democratic Republic of the Congo.

Received: 30 December 2020 Accepted: 15 December 2021 Published online: 20 December 2021

\section{References}

1. Cucinotta D, Vanelli M. WHO declares COVID-19 a pandemic. Acta Biomed. 2020;91(1):157-60. 
2. WHO September report. https://www.who.int/publications/m/item/ weekly-epidemiological-update---28-september-2020.

3. Zhu J, Ji P, Pang J, Zhong Z, Li H, He C, et al. Clinical characteristics of 3062 COVID-19 patients: a meta-analysis. J Med Virol. 2020. https://doi.org/10. 1002/jmv.25884.

4. Worldometer. DR Congo Population USA2020 [Available from: https:// www.worldometers.info/world-population/democratic-republic-of-thecongo-population/.

5. Roy S, Khalse M. Epidemiological determinants of COVID-19-related patient outcomes in different countries and plan of action: a retrospective analysis. Cureus. 2020;12(6):e8440.

6. Amoo EO, Adekeye O, Olawole-Isaac A, Fasina F, Adekola PO, Samuel GW, et al. Nigeria and Italy divergences in coronavirus experience: impact of population density. Sci World J. 2020. https://doi.org/10.1155/2020/ 8923036.

7. Nachega JB, Ishoso DK, Ookoye JO, Hermans MP, Machekano RN, Sam-Agudu NA, et al. Clinical characteristics and outcomes of patients hospitalized for COVID-19 in Africa: early insights from the Democratic Republic of the Congo. Am J Trop Med Hyg. 2020;103(6):2419-28.

8. Kimmelman J, Weijer C, Meslin EM. Helsinki discords: FDA, ethics, and international drug trials. Lancet. 2009;373:13-4.

9. The Seventh Report of The Joint National Committee (JNC) on prevention, detection, evaluation and treatment of high blood pressure (HBP). JAMA 2003; 289: 2560-2572

10. Huang C, Wang Y, Li X, Ren L, Zhao J, Hu Y, et al. Clinical features of patients infected with 2019 novel coronavirus in Wuhan, China. Lancet. 2020:395:497-506.

11. American Diabetes Association. Position statement, diagnosis and classification of diabetes mellitus. Diabetes Care 2008; 31 (Suppl 1): S55-60.

12. Inker $L A$, Astor $B C$, Fox CH, Isakova T, Lash JP, Peralta CA, et al. KDOQI US commentary on the $2012 \mathrm{KDIGO}$ clinical practice guideline for the evaluation and management of CKD. Am J Kidney Dis. 2014;63(5):713-35.

13. ARDS Definition Task Force, Ranieri VM, Rubenfeld GD, Thompson BT, Ferguson ND, Cadwell $E$, et al. Acute respiratory distress syndrome: the Berlin Definition. JAMA. 2012;307:2526-33.

14. Khwaja A. KDIGO clinical practice guidelines for acute kidney injury. Nephron Clin Pract. 2012;120:c179-84.

15. Sandoval $Y$, Januzzi JL, Jaffe AS. Cardiac troponin for assessment of myocardial injury in Covid-19. JACC. 2020;76(10):1244-58.

16. Francone M, lafrate F, Masci GM, Coco S, Cilia F, Manganaro L, et al. Chest CT score in COVID-19 patients: correlation with disease severity and short-term prognosis. Eur Radiol. 2020;30:6808-17.

17. Bepouka B, Mandina M, Makulo JR, Longokolo M, Odiao O, Mayasi N, et al. Predictors of mortality in COVID-19 patients at Kinshasa University Hospital, Democratic Republic of the Congo from March to June 2020. Pan Afr Med J. 2020;37:105. https://doi.org/10.11604/pamj.2020.37.105.25279.

18. The Epidemiological Characteristics of an Outbreak of 2019 Novel coronavirus diseases (COVID-19)—China, 2020[J]. China CDC Weekly, 2020, 2(8): 113-122

19. Ruan Q, Yang K, Wang W, Jiang L, Song J. Clinical predictors of mortality due to COVID-19 based on an analysis of data of 150 patients from Wuhan. China Intensive Care Med. 2020;46(5):846-8.

20. Tian W, Jiang W, Yao J, Nicholson CJ, Li RH, Sigurslid HH, et al. Predictors of mortality in hospitalized COVID-19 patients: a systematic review and meta-analysis. J Med Virol. 2020;92(10):1875-83.

21. Xu J, Yang X, Yang L, Zou X, Wang Y, Wu Y, et al. Clinical course and predictors of 60-day mortality in 239 critically ill patients with COVID-19: a multicenter retrospective study from Wuhan, China. Crit Care. 2020;24(1):394.

22. Yang $X, Y u Y, X u J$, Shu H, Xia J, Liu H, et al. Clinical course and outcomes of critically ill patients with SARS-CoV-2 pneumonia in Wuhan, China: a single-centered, retrospective, observational study. Lancet Respir Med. 2020;8(5):475-81.

23. Arentz M, Yim E, Klaff L, Lokhandwala S, Riedo FX, Chong M, et al. Characteristics and outcomes of 21 critically ill patients with COVID-19 in Washington State. JAMA. 2020;323(16):1612-4.

24. Du RH, Liang LR, Yang CQ, Wang W, Cao TZ, Li M, Guo GY, et al. Predictors of mortality for patients with COVID-19 pneumonia caused by SARSCoV-2: a prospective cohort study. Eur Respir J. 2020;55(5):2000524.

25. Ciceri F, Castagna A, Rovere-Querini P, De Cobelli F, Ruggeri A, Galli L, et al. Early predictors of clinical outcomes of COVID-19 outbreak in Milan, Italy. Clin Immunol. 2020:217:108509.
26. Williamson EJ, Walker AJ, Bhaskaran K, Bacon S, Bater C, Morton CE, et al. factors associated with COVID-19 related death using OpenSAFELY. Nature. 2020;584:430-6.

27. Kang SJ, Jung SI. Age-related morbidity and mortality among patients with COVID-19. Infect Chemother. 2020;52(2):154-64.

28. Pan F, Yang L, Li Y, Liang B, Li L, Ye T, Li L, et al. Factors associated with death outcome in patients with severe coronavirus disease-19 (COVID19): a case-control study. Int J Med Sci. 2020;17(9):1281-92.

29. Hu R, Han C, Pei S, Yin M, Chen X. Procalcitonin levels in COVID-19 patients. Int J Antimicrob Agents. 2020;56(2):106051.

30. Lippi G, Plebani M. Procalcitonin in patients with severe coronavirus dis ease 2019 (COVID-19): a meta-analysis. Clin Chim Acta. 2020;505:190-1.

31. Han J, Gatheral T, Williams C. Procalcitonin for patient stratification and identification of bacterial co-infection in COVID-19. Clin Med. 2020;20(3): e47. https://doi.org/10.7861/clinmed.Let.20.3.3.

32. Zhang JJ, Dong $X$, Cao YY, Yuan YD, Yang YB, Yan YQ, et al. Clinical characteristics of 140 patients infected with SARS-CoV-2 in Wuhan, China. Allergy. 2020;75(7):1730-41.

33. Lu R, Zhao X, Li J, Niu P, Yang B, Wu H, et al. Genomic characterisation and epidemiology of 2019 novel coronavirus: implications for virus origins and receptor binding. Lancet. 2020;395:565-74.

34. Guan WJ, Ni ZY, Hu Y, Liang WH, Ou CQ, He JX, et al. Clinical characteristics of coronavirus disease 2019 in China. N Engl J Med. 2020;382:1708-20.

35. Lippi G, Plebani M. Laboratory abnormalities in patients with COVID-2019 infection. Clin Chem Lab Med. 2020;58(7):1131-4.

36. Ronco C, Reis T, Husain-Syed F. Management of acute kidney injury in patients with COVID-19. Lancet Respir Med. 2020;8(7):738-42.

37. Cheng Y, Luo R, Wang K. Kidney disease is associated with in-hospital death of patients with COVID-19. Kidney Int. 2020;97:829-38.

38. Robbins-juarez SY, Qian L, King KL, Stevens JS, Husain SA, Radhakrishnan J, et al. Outcomes for patients with covid-19 and acute kidney injury: a systematic review and meta-analysis. Kidney Int Rep. 2020;5(8):1149-60.

39. Gabarre P, Dumas G, Dupont T, Darmon M, Azoulay E, Zafrani L. Acute kidney injury in critically ill patients with COVID-19. Intensive Care Med. 2020;46(7):1339-48.

40. Liu R, Ma Q, Han H, Su H, Liu F, Wu K, et al. The value of urine biochemical parameters in the prediction of severity of COVID-19. Clin Chem Lab Med. 2020:58:1121-4.

41. Karras A, Livrozet M, Lazareth H, Benichou N, Hulot JB, Fayol A, et al. Proteinuria and clinical outcomes in hospitalized COVID-19 patients. CJASN. 2021;16(4):514-21.

\section{Publisher's Note}

Springer Nature remains neutral with regard to jurisdictional claims in published maps and institutional affiliations.

Ready to submit your research? Choose BMC and benefit from

- fast, convenient online submission

- thorough peer review by experienced researchers in your field

- rapid publication on acceptance

- support for research data, including large and complex data types

- gold Open Access which fosters wider collaboration and increased citations

- maximum visibility for your research: over 100M website views per year

At BMC, research is always in progress.

Learn more biomedcentral.com/submissions 